\title{
Correction to: Role of low-level laser therapy added to facial expression exercises in patients with idiopathic facial (Bell's) palsy
}

Banu Ordahan $^{1} \cdot$ Ali yavuz Karahan ${ }^{1}$

Published online: 17 June 2019

(C) Springer-Verlag London Ltd., part of Springer Nature 2019

Correction to: Lasers in Medical Science

https://doi.org/10.1007/s10103-017-2195-9

The online version of the original article can be found at https://doi.org/ 10.1007/s10103-017-2195-9

Banu Ordahan

banuordahan@gmail.com

1 Department of Physical Medicine and Rehabilitation, Konya Education and Training Hospital, Yazırmah, Selçuklu,

Konya, Turkey 
The published version contains a mistake in Figure 1. Below is the correct figure.

Fig. 1 Flow diagram
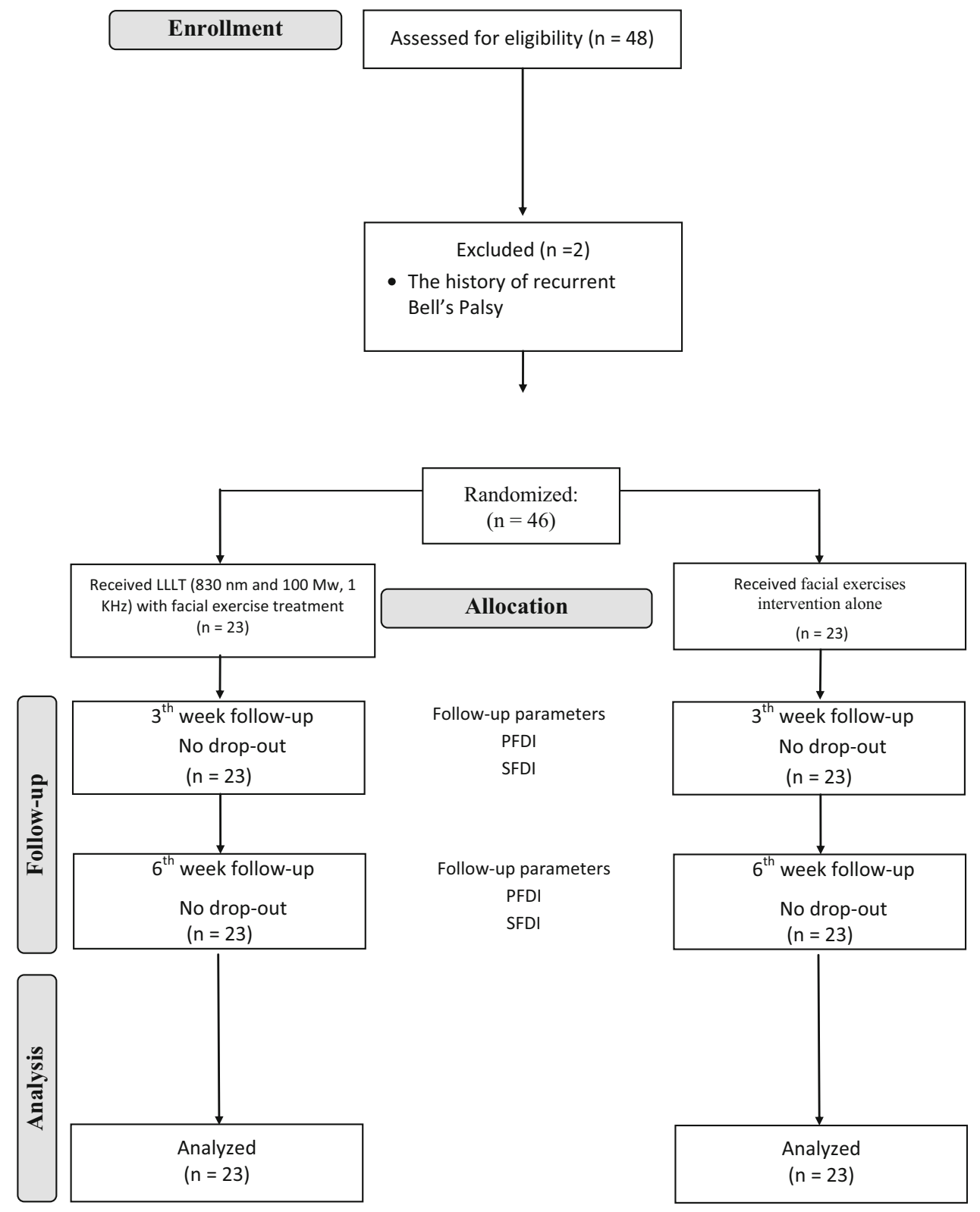

LLLT: Low-level laser treatment, PFDI: Facial disability index physical; SFDI: Facial disability index social

Publisher's note Springer Nature remains neutral with regard to jurisdictional claims in published maps and institutional affiliations. 